\title{
Knowledge, attitudes and practices about malaria in Cabo Verde: a country in the pre-elimination context
}

Adilson José DePina ${ }^{1,2^{*}}$ (D), Abdoulaye Kane Dia ${ }^{3}$, Antonieta de Ascenção Soares Martins ${ }^{4}$, Maria Celina Ferreira ${ }^{5}$, António Lima Moreira ${ }^{6}$, Silvania Veiga Leal ${ }^{7,8}$, Cecílio Mendes Pires ${ }^{9}$, Jaelsa Mira Gomes Moreira ${ }^{10}$, Maria Filomena Tavares ${ }^{11}$, Aires Januário Fernandes da Moura ${ }^{12}$, José Manuel Pereira ${ }^{4,13}$, Ousmane Faye ${ }^{3}$, Ibrahima Seck ${ }^{14}$ and El Hadji Amadou Niang ${ }^{3,15}$

\begin{abstract}
Background: Malaria in Cape Verde is unstable, with a sporadic and seasonal transmission of low endemicity. In this sense, the community perceptions regarding malaria transmission, their attitudes and practices against the disease are very important to understand and to better develop the best strategical policies to achieve malaria elimination goal. This study aim to assess the knowledge, attitudes and practices (KAP) of Cape Verdean population about malaria, a country in the elimination step of disease.

Methods: A cross-sectional malaria KAP Survey was performed at the household level. A structured open questionnaire was developed and applied to residents of randomly selected households from 5 islands and 15 municipalities in Cape Verde. Correlation analyses were performed using a logistic regression model to determine the factors that are associated with the complete knowledge of the population about malaria.

Results: A total of 1953 fully completed questionnaires were analysed, with majority of questionnaires administered in Santiago island (68.3\%), mainly in the capital city of Praia, 38.43\%. About $88 \%$ of the population knew the correct form of transmission, $96 \%$ had knowledge that the entire population is at risk of malaria and identified the main symptoms. Regarding the attitudes, 58\% seek treatment atthe nearest health structure upon the apparition of the symptoms, $64 \%$ in the first $24 \mathrm{~h}$ and $88 \%$ within the first $48 \mathrm{~h}$. More than $97 \%$ have heard about mosquito nets but only $19 \%$ used it. In practice, $53 \%$ use coils, $45 \%$ rely on household sprays and $43 \%$ have benefited from IRS. About $90 \%$ received information about malaria from media, mainly the TV and the radio ( 83 and $43 \%$, respectively). In summary, 54\% of the population has complete knowledge of the disease.

Conclusion: The population of Cape Verde has a high level of knowledge about malaria, including its transmission, main symptoms and preventive and control measures. However, some gaps and misunderstandings have been noticed and contribute to the insufficient community involvement in actions against malaria. Therefore, is necessary to increase the knowledge of the population, leading to their full ownership and participation in community actions to contribute to the malaria elimination in the country.
\end{abstract}

Keywords: KAP, Knowledge, Attitudes, Practices, Malaria elimination, Cape Verde

\footnotetext{
* Correspondence: Adilson.Pina@ccssida.gov.cv

${ }^{1}$ Ecole Doctorale des Sciences de la Vie, de la Santé et de l'Environnement

(ED-SEV), Université Cheikh Anta Diop (UCAD) de Dakar, Dakar, Sénégal

2Programa de Pré-Eliminação do Paludismo, CCS-SIDA. Ministério da Saúde e

da Segurança Social, Avenida Cidade Lisboa, Prêdio Bô Casa, $1^{\circ}$ Andar; CP,

855 Praia, Cabo Verde

Full list of author information is available at the end of the article
}

(c) The Author(s). 2019 Open Access This article is distributed under the terms of the Creative Commons Attribution 4.0 International License (http://creativecommons.org/licenses/by/4.0/), which permits unrestricted use, distribution, and reproduction in any medium, provided you give appropriate credit to the original author(s) and the source, provide a link to the Creative Commons license, and indicate if changes were made. The Creative Commons Public Domain Dedication waiver (http://creativecommons.org/publicdomain/zero/1.0/) applies to the data made available in this article, unless otherwise stated. 


\section{Background}

Despite being a preventable and curable disease, malaria remains a major public health problem with a huge economic burden. In 2017, approximately 219 million cases responsible for about 451,000 malaria deaths were recorded worldwide. The African region accounting for more than $90 \%$ cases and 93\% of all deaths remains the most affected of all the World Health Organisation (WHO) regions [1].

Currently, of the 91 countries with ongoing malaria transmission, 14 are located in sub-Saharan Africa and account, with India, for more than $80 \%$ of the global malaria burden. Therefore, the WHO has rolled out a significant malaria control effort worldwide to reduce the disease incidence and to drive toward malaria elimination where feasible. Consequently, the estimated global malaria incidence has decreased by $18 \%$, from 72 to 59 cases per 1000 populations at risk from 2010 to 2017 [1]. In 2017, Paraguay and Uzbekistan were certified malaria-free by the WHO, while 46 countries reported less than 10,000 malaria cases, and 26 (including the Cabo Verde) having the potential to eliminate malaria by 2020 .

Historically, malaria has been officially reported in the Archipelago of Cape Verde since the sixteenth century when the islands were settled [2]. During that time, the disease was endemic and seasonal with the risk of outbreaks, especially during years of high rainfall records, with together high migrants' flux from malaria hyperendemic regions, namely São Tomé and Príncipe, Angola or Guinea- Bissau [3].

Therefore, until the $1940 \mathrm{~s}$, malaria represented a serious public health problem in Cape Verde, with severe epidemics affecting annually more than 10,000 persons and responsible for more than 200 deaths [4]. The implementation of semi-annual campaigns of Indoor Residual Spray (IRS) in all the lived islands between 1967 and 1972 then between 1983 and 1985, have resulted to the elimination of the disease in the country. As such the country has been declared free of malaria twice. But the diseases resurged respectively 5 and 3 years afterwards the first and the second elimination periods.

Since 1987, started the third period characterized by recurrent malaria outbreaks, mainly in the island of Santiago where all the indigenous cases occurred up to 2003 with the report of local malaria transmission in the island of Boavista [5]. However, conversely to autochthonous cases, imported cases have been reported in almost the entire national territory [6].

Nowadays, in Cape Verde malaria is seasonal and unstable, with the sporadic transmission of low endemicity. The transmission varies annually with a peak during the rainy season, responsible for the temporal fluctuation of malaria morbidity as observed in areas of risk of malaria transmission across the Archipelago. In the islands of
Santiago and Boavista, where all the indigenous cases were recorded recently, malaria affects mostly young men of an average age of 20 years, while children under five and the pregnant women seem to be less impacted. Noteworthily, no malaria infection has been diagnosed in a pregnant women in 2017 [6].

With the advances in the fight against malaria in Cape Verde, the archipelago has been designated by the WHO as one of the countries with the potential to eliminate malaria by 2020. Despite the significant successes made so far against the disease, including its elimination twice from the archipelago in the past, it is worth noting the failure to consolidate and maintain the malaria-free status. Thegoal of achieving zero local transmission by 2020, has been challenged by the recent malaria outbreak with 423 indigenous cases recorded in 2017 [7].

Considering the complexity and challenges for malaria elimination, there is no doubt that all malaria preventive and control interventions should be community-based and requires full ownership from the affected local populations. However, their appropriation of any control programme, as well as their willingness to accept interventions, are influenced by their knowledge and perceptions about diseases and interventions. Moreover, the local population daily behaviour also highly crucial is determined by several other factors related to their level of knowledge about malaria [8].

Health education to enhance and increase knowledge and awareness in the population, through community engagement leads to good participation in the interventions for malaria control and elimination. Whereby in an area with low malaria cases, as Cape Verde, the community diagnosis about the social and human behavioural aspects, becomes essential before all intervention [8]. Findings from KAP surveys can be formative to guide malaria in vector control, case management, implementation of behavioural interventions, promotion of healthseeking behaviour and ultimately enhance community participation and engagement [9-14]. In Cape Verde archipelago, with islands where locally acquired malaria cases have not been recorded for decades [6], this malaria KAP survey provide key elements not only to the NMCP in the elimination context, to empower local populations and enhance their ownership and responsibility, but also to promote the application of actionoriented and participatory approaches. Therefore, the objective of this study was to evaluate the KAP about malaria among Cape Verdean population and to provide insights on effective malaria actions to get back on the track of the malaria elimination goal in the country.

\section{Methods}

The country

Cabo Verde is an archipelago of ten volcanic, of which nine islands are inhabited and islands and several islets. 
The islands are divided into two groups located toward the western coast of the African continent.

The country covers an area of $4033 \mathrm{~km}^{2}$ and is located between the $17^{\circ} 12$ 'and $14^{\circ} 48^{\prime}$ latitudes and $22^{\circ} 44^{\prime}$ ' and $25^{\circ} 22^{\prime}$ longitudes. The islands are relatively sparse, and the relief is mostly rocky, with only about $10 \%$ of the soils suitable for agriculture (Fig. 1).

According to the 2010 National Census, the population of Cabo Verde has increased by $1.23 \%$, from 434,625 to 491,575 inhabitants between 2000 and 2010. About 62\% of the population live in urban areas with a slight predominance of women. Overall, children under 15 years of age represent $31.7 \%$ of the general population and the average age increased from 18 to 22 years. The average household size is 4.2 persons per household. Despite being a country of emigrants, the country has also become, in recent decades, an important destination for immigrants, mainly from African countries, but also from Europe and Asia. Indeed, in 2010, 2.9\% (14.373) of the country residents were migrants [15].

\section{The KAP survey}

A cross-sectional malaria KAP Survey was performed between April to May 2017 at the household-level, using semi-structured questionnaire (available in Additional file 1) adapted and administrated to residents of randomly selected households from 15 municipalities in five out of the nine islands of the country, namely, São Vicente, Boavista, Maio, Santiago and Fogo. The interviews were carried out by 65 municipal health technicians, trained for this purpose, and supervised by 8 coordinators.

A random stratification method was used to choose the study participants to obtain a representative sample. Samples were chosen based on the characteristics of the household, and interview of the head of the household or the responsible adult, using a standard questionnaire. The sample size was calculated according to the number of households and the average number of individuals per family in each municipality as recorded from the last population census carried out in Cape Verde [9]. Therefore, samples were selected based on the population

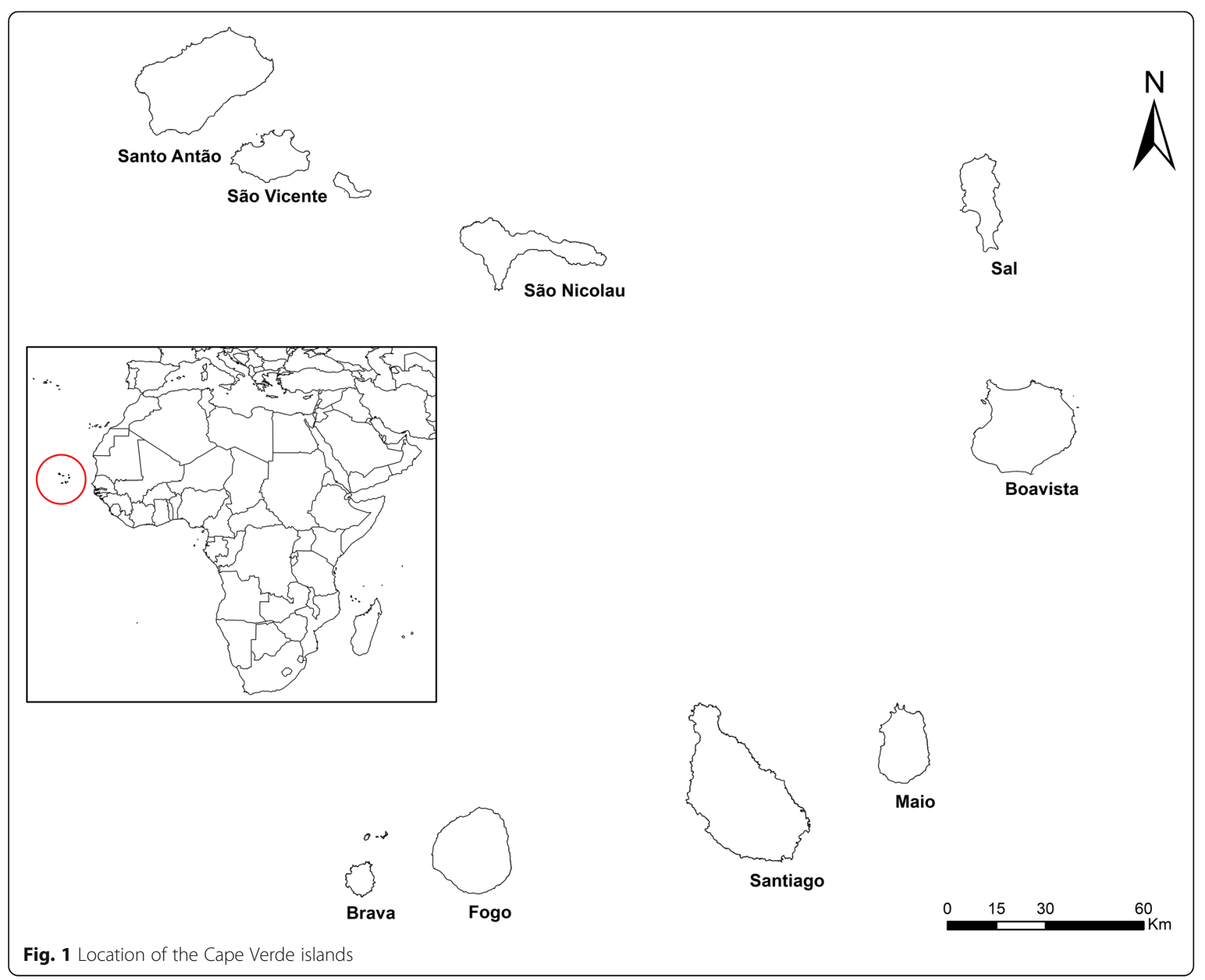


proportion with absolute precision $(d)$ of $2.5 \%$, a confidence interval of $95 \%(z=1.96)$ and $p$-value set at 0.5 . Given the objectives of the study, the samples size was calculated taking into account the target population, the resident population and the number of family dwellings occupied as habitual residence. Thehe quality of questionnaire data was monitored daily.

\section{Selection of variables}

The questionnaire was structured to take approximately $25 \mathrm{~min}$ and included open and closed questions, structured in five distinct parts: (i) socio-economic and demographic characteristics, (ii) assessment of knowledge, (iii) attitudes and (iv) and preventive practices related to malaria, including the use of mosquito nets, and (v), a final section concerned the source of communication and information about the control of malaria in the community.

After answering all the questions, the participant was asked to guide the field team inside and around their home, with the purpose of completing the checklist. At the end of the interview, each interviewer provides the participant with the summary of the main information collected for review for validation by respondents.

\section{Data analysis}

A total of 1953 semi-structured interviews were conducted and the data collected were analysed using the SPSS 21.0 software version. The results were presented as descriptive analysis, in frequencies and percentage for categorical variables to determine the level of knowledge, the main attitudes and practices of the population. The qualitative data were analysed using the documentary thematic analysis in accord with the contents of the interviews.

Additionally, the population's complete knowledge about malaria was further analysed, to determine the percentage of respondents who simultaneously knows the form of transmission of the disease, one of the main symptoms of the disease and a preventive measure against the disease. Subsequently, a detailed analysis was carried out through logistic regression, where the variables were selected based on the significant association in relation to the complete knowledge of malaria, taking into account the relevance to the research question [11]. For the logistic regression analysis, thus selected variables were dichotomized into two categories with presence of certain characters/conditions = 1 and absence $=0$. A univariate analysis was conducted with the outcome variable to calculate crude odds ratios and a multivariate analysis, selected variables were included into the model to calculate the adjusted odds ratio and a Statistical significance with $p$-value $\leq 0.05[16,17]$.

\section{Ethical clearance}

The study protocol was approved by the National Ethics and Health Research Committee (CNEPS), in accordance with resolution 18/2017. Participation was voluntary, and no personal identification document was recorded during the data collection. All data was stored in a protected file with access to information limited to a small team in charge of piloting the study. The confidentiality of the data provided by the respondents was highlighted as one of the formative modules in the training of the interviewers.

The purpose, procedures, duration of the study and related risks and benefits were all clearly explained to participants prior to their participation in any of the steps in the data collection process. Before signing the consent form for participation, participants had the opportunity to ask clarifying questions about the study. Participants who agreed to take part in the study were invited to describe the study in order to clarify any misconception and to ascertain whether the objectives were assimilated. The speakers gave explanations about the possibility of withdrawing from interviews or group discussions at any time. The terms of consent for this study will be destroyed as soon as all analyses of the results are completed.

\section{Results}

\section{Descriptive analysis}

A total of 1.953 fully completed questionnaires from the interviewed families were used in the final analysis of the KAP study in the country. Majority of the questionnaires were carried out in the capital, Praia (749), followed by São Vicente (15.9\%), Santa Catarina (8.4), and Santa Cruz (5.6\%) (Table 1).

The average age of respondents was 44 years, ranging from 15 to 64 years. The majority of participants were female $(72.0 \%)$, youth (23.8\%, aged between 25 to 34 years), single $(51.1 \%)$ and with primary or secondary school level (47.7 and 32.9\%, respectively). At least one person works with a fixed salary in about $43.2 \%$ of the households. However, in some cases, in $33,7 \%$ and $12,5 \%$ of respondents, has 02,03 or more people, respectively, are employed and earn a salary (Table 2).

\section{Information about malaria}

Malaria was the fifth (5 in 6), disease identified in the study communities $(8$, and all the respondents have already heard about it. Moreover, the majority of the respondents (85.3\%) knew that malaria is transmitted through mosquito bites. Analysis by age showed that the level of knowledge about malaria transmission varies between different age range, being the highest in people with $\geq 41$ years old (Table 3 ). About $96 \%$ of the respondents were aware that all the population is at risk of contracting malaria. 
Table 1 Number of interviews by municipalities and island

\begin{tabular}{llll}
\hline Island & Municipality & Percentage (\%) & $\mathrm{n}$ \\
\hline São Vicente & São Vicente & 15.9 & 310 \\
Boa Vista & Boa Vista & 3.6 & 71 \\
Maio & Maio & 2.3 & 44 \\
Santiago & Tarrafal & 4.2 & 83 \\
& Santa Catarina & 8.4 & 165 \\
& Santa Cruz & 5.6 & 110 \\
& Praia & 38.4 & 749 \\
& São Domingos & 1.1 & 22 \\
& São Miguel & 5.5 & 108 \\
& São Salvador do Mundo & 1.5 & 29 \\
& São Lourenço Orgãos & 1.6 & 32 \\
& Ra Grande Santiago & 2.0 & 40 \\
& Mosteiros & 2.5 & 48 \\
& São Filipe & 5.4 & 106 \\
& Santa Catarina & 1.8 & 36 \\
& TOTAL & 100.0 & 1953 \\
\hline
\end{tabular}

The principal malaria symptoms identified in the study were fever $(83 \%)$, headaches $(62 \%)$ and muscle pains (36\%) (Fig. 2).

\section{Treatment seeking behaviour}

The population behaviour when facing malaria symptoms was analysed and revealed that $58 \%$ of the interviewed people seek for treatment at the nearest health structure, while $39 \%$ rely on self-medication and 3\% seek for traditional methods of medication. The majority of people $(64 \%)$ visit health structures or seek for treatment within the $24 \mathrm{~h}$ after the occurrence of first suspected malaria symptoms, against $24 \%$ that do it between 24 and $48 \mathrm{~h}$, and $4 \%$ after $48 \mathrm{~h}$ (Fig. 3). However, when questioned about the best attitudes when facing malaria symptoms, $91 \%$ of the respondent's reply "to immediately go to the nearest health structure". In general, $86 \%$ of the people knew that delayed treatment seeking as well as delayed and inadequate treatment of malaria can lead to death or sequels.

Despite being yet underused in Cape Verde, insecticideimpregnated mosquito nets acceptability among the study population revealed that $97 \%$ of them have heard about mosquito nets, but only $19 \%$ were using them. However, $91 \%$ are open to the use if made freely available, against $5 \%$ who won't and $4 \%$ who don't know.

When asked who is in charge for malaria control in the community, $48 \%$ of the interviewed replied: "the population", 33\% "the health structure", 13\% "the government" and $18 \%$ thinks that "all the above" are. However, $3 \%$ of the respondents have designed other entities than the three above.
Table 2 Characteristics of the KAP study population in Cabo verde 2017

\begin{tabular}{|c|c|c|}
\hline \multirow[t]{2}{*}{ Characteristics } & \multicolumn{2}{|l|}{ Participation } \\
\hline & Percentage (\%) & $n$ \\
\hline \multicolumn{3}{|l|}{ Age range } \\
\hline$\leq 29$ & 25.3 & 495 \\
\hline $30-39$ & 21.1 & 412 \\
\hline$\geq 40$ & 53.6 & 1046 \\
\hline \multicolumn{3}{|l|}{ Sex } \\
\hline Male & 28.0 & 546 \\
\hline Female & 72.0 & 1407 \\
\hline \multicolumn{3}{|l|}{ Civil status } \\
\hline Single & 51.1 & 998 \\
\hline Married & 17.0 & 332 \\
\hline Union / marital lives & 24.0 & 469 \\
\hline Divorced / Separated & 1.8 & 36 \\
\hline Widowed & 6.0 & 118 \\
\hline \multicolumn{3}{|l|}{ Level of education } \\
\hline Illiterate (never went to school) & 14.4 & 281 \\
\hline Primary (1st to 6th grade) & 47.7 & 931 \\
\hline Secondary (7th to 12 th year) & 32.9 & 642 \\
\hline Higher & 5.1 & 99 \\
\hline \multicolumn{3}{|l|}{ Number of people working } \\
\hline 0 & 10.6 & 207 \\
\hline 1 & 43.2 & 844 \\
\hline 2 & 33.7 & 658 \\
\hline $3+$ & 12.5 & 244 \\
\hline \multicolumn{3}{|l|}{ Family Income (ECV) } \\
\hline Less than 10,000 & 28.4 & 555 \\
\hline 10,000 to 25,000 & 44.1 & 862 \\
\hline 25,000 to 50,000 & 15.7 & 307 \\
\hline 50,000 to 75,000 & 4.4 & 85 \\
\hline Greater than 75,000 & 2.7 & 53 \\
\hline N/A & 4.7 & 91 \\
\hline Total & 100.0 & 1953 \\
\hline
\end{tabular}

ECV Cape Verdean escudos (1 EUR $=110.265$ ECV), N/A Data not available

People perceive that coils (53\%), spraying houses (45\%), using repellent on exposed body parts $(29 \%)$ or burying rubbish and sleeping underneath mosquito net $(15 \%)$ protect against mosquito bites. Regarding which actions is considered the most important for a community-based malaria control, $53 \%$ of the interviewed indicated the involvement of all the country population, or encourage the community participation (32.4\%), the participation of the media $(13.5 \%)$, private sector $(4.3 \%)$, church and pastors $(3.7 \%)$ and $0.9 \%$ had no idea.

Questioned about the behaviour adopted when receiving a visit from health professionals, $96.2 \%$ said they 
Table 3 The level of knowledge of the Cape Verdean population about malaria transmission by sex and age (\%)

\begin{tabular}{|c|c|c|c|c|c|c|c|}
\hline Characteristics & Mosquito bites & Contact with people with malaria & Contaminated food & Flies & Poor personal hygiene & Others & $n$ \\
\hline \multicolumn{8}{|l|}{ Age range } \\
\hline$\leq 29$ & 22.0 & 0.1 & 0.3 & 0.2 & 0.7 & 1.3 & 495 \\
\hline $30-39$ & 19.3 & 0.4 & 0.1 & 0.1 & 0.9 & 0.5 & 412 \\
\hline$\geq 40$ & 44.0 & 0.4 & 0.8 & 0.7 & 3.4 & 2.4 & 1046 \\
\hline \multicolumn{8}{|l|}{ Sex } \\
\hline Male & 87.5 & 0.7 & 0.4 & 0.4 & 5.5 & 3.5 & 546 \\
\hline Female & 84.4 & 0.6 & 1.4 & 1.1 & 4.8 & 4.4 & 1407 \\
\hline Total & 85.3 & 0.8 & 1.1 & 0.9 & 5.0 & 4.1 & 1953 \\
\hline
\end{tabular}

always receive them, but $0.5 \%$ of the study population asked them to come back later and $0.3 \%$ do not receive them because of another commitment, while $1.3 \%$ claim another reason and $1.7 \%$ preferred to not respond to that question. The assessment of population knowledge about IRS activities in the country showed that $88.6 \%$ of them have had their house sprayed previously, against $11 \%$ who never benefited from the intervention, and $0.4 \%$ preferred not to respond. The majority of the population (95.8\%) knew that IRS is beneficial for controlling mosquitos against $0.5 \%$ who didn't think so, while $0.7 \%$ did not know and $3.0 \%$ did not respond.

\section{Sources of information about malaria}

The main sources of information about malaria, including transmission, main symptoms and preventive measures were analysed. The results indicate that $90.4 \%$ of respondents received information about malaria, and the media are major sources of information. Being the television the principal medium (83\%) followed by radio (43\%). Home visit by health technicians (30\%) was designed as other source of information (Fig. 4).

Overall, the majority of the population (89.2\%) has a good understanding of information received about malaria, and only a few (6.7\%) claimed the contrary. Among those having not understood the information, some reasons were appointed as, little information provided (24\%), lack of adapted information for lay people (19\%), not having a television (15\%), not listening radio (8\%), or lack of understanding of the technical language $(8 \%)$, or other imprecise reasons (18\%). When asked which ways they would like to receive information about malaria, the majority (59\%) prefers being informed through the television and visits of health workers (51\%) (Fig. 5).

When asked in which language they prefer being informed about malaria, the majority $(86 \%)$ answered the Cape Verdean Creole, while 10\% of the population preferred the Portuguese and 3\% in both. Other preferred languages were English or French (1\% each).

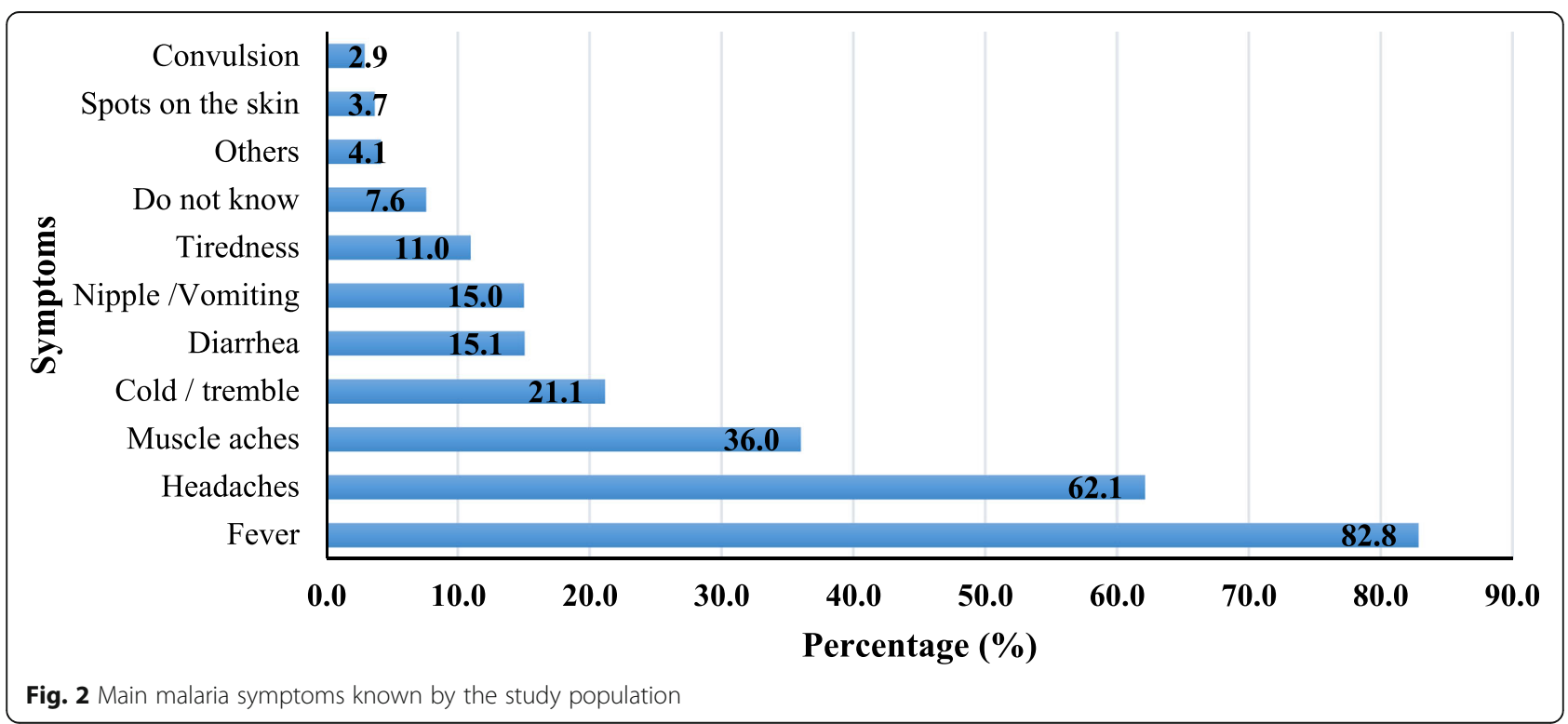




\section{Before 24 hours $₫$ Before 48 hours $₫$ After 48 hours $₫$ Others/ND}

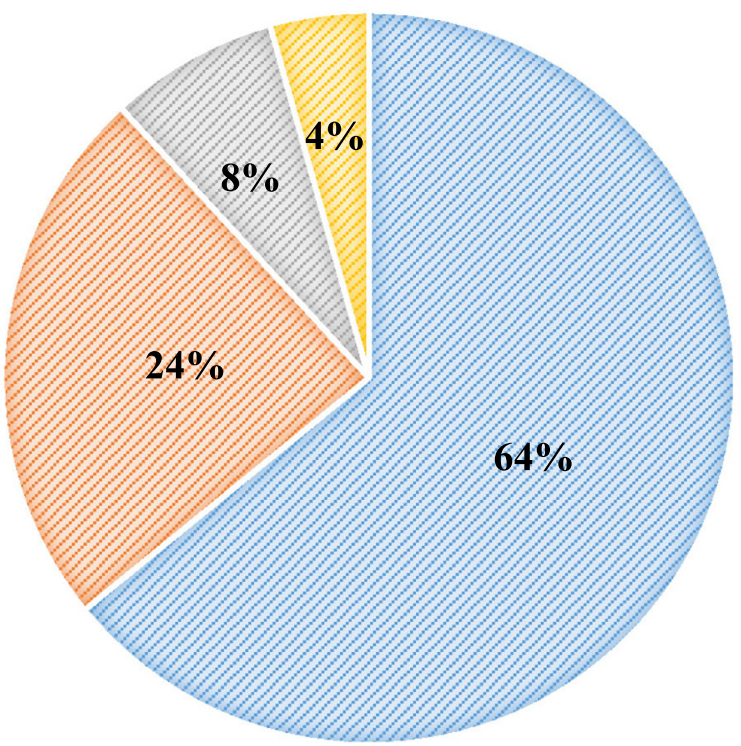

Fig. 3 Time after which the cape verdean population see the health facility after the symptoms (of the fever), in percentage (\%)

\section{Complete knowledge about malaria}

We also assessed the overall level of the complete knowledge of the study population about malaria, including all the aspect of the disease transmission routes, at least one of the main symptoms of the disease and one preventive measure of the disease. The results show that $54 \%$ of the population had complete knowledge about the disease, being higher among men (60.3\%) than women (52\%). On the other hand, the complete knowledge was higher within the age group 35-39 years (60.7\%), and within people with a higher level of education (75.8\%) (Table 4).

The visits of dwelling after each interview has allowed to cross-check and complete as much as possible the questionnaire. During the visits, the main findings of the population behaviours against mosquitoes were the adequate coverage of water containers (in 91\% of visited houses), cleanness of animal's troughs (57\%), and fewer plants pots with sand (33\%) (Fig. 6).

\section{Multivariate logistic regression}

Using the logistic regression model [11], the following factors were associated with the complete knowledge about malaria (Table 5). When analysed, the scholar level (AOR 1.15; CI 1.0 to $1.0 ; p=0.02$ ), the resident area, in this case municipality $(\mathrm{AOR}=0.9$; $\mathrm{CI} 0.6$ to 0.8 ; $p=0.00)$ and the age $(\mathrm{AOR}=0.7 ; \mathrm{CI} 0.6$ to $0.2 ; \mathrm{p}=0.00)$

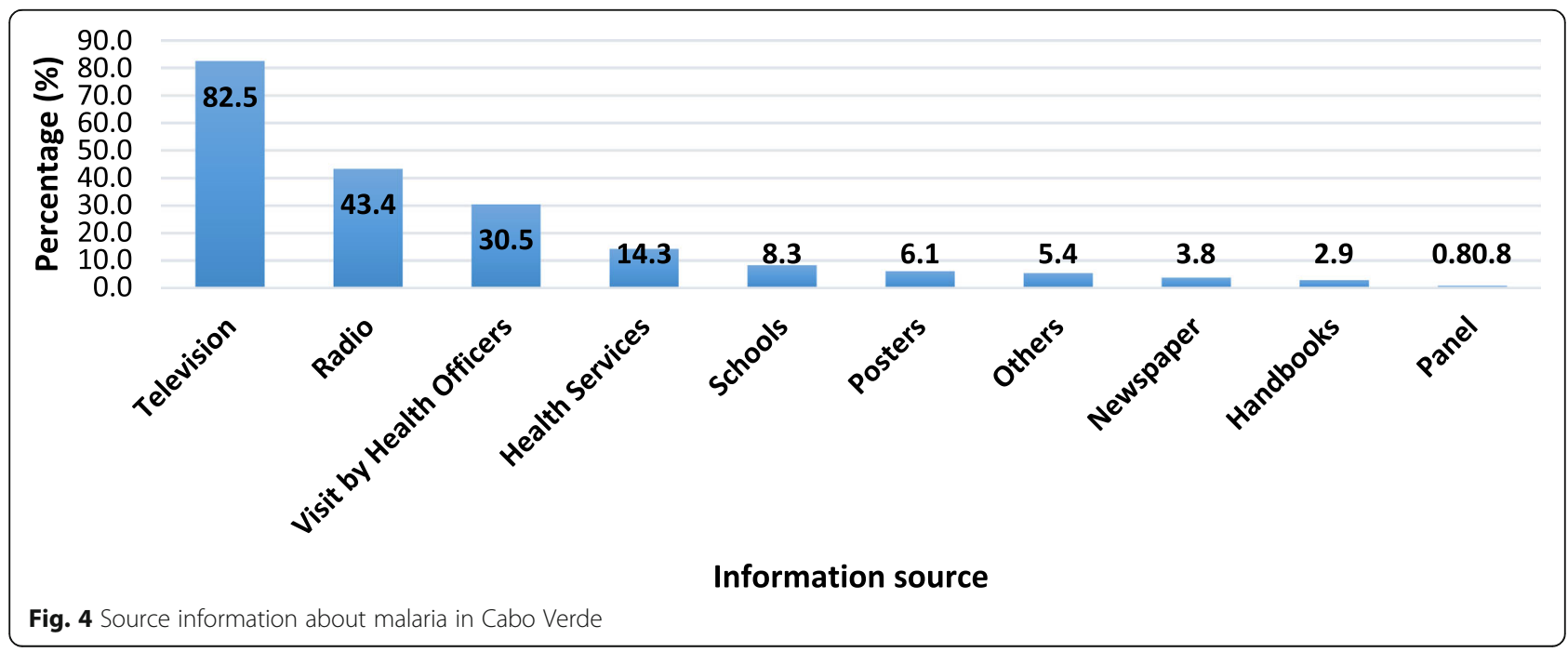




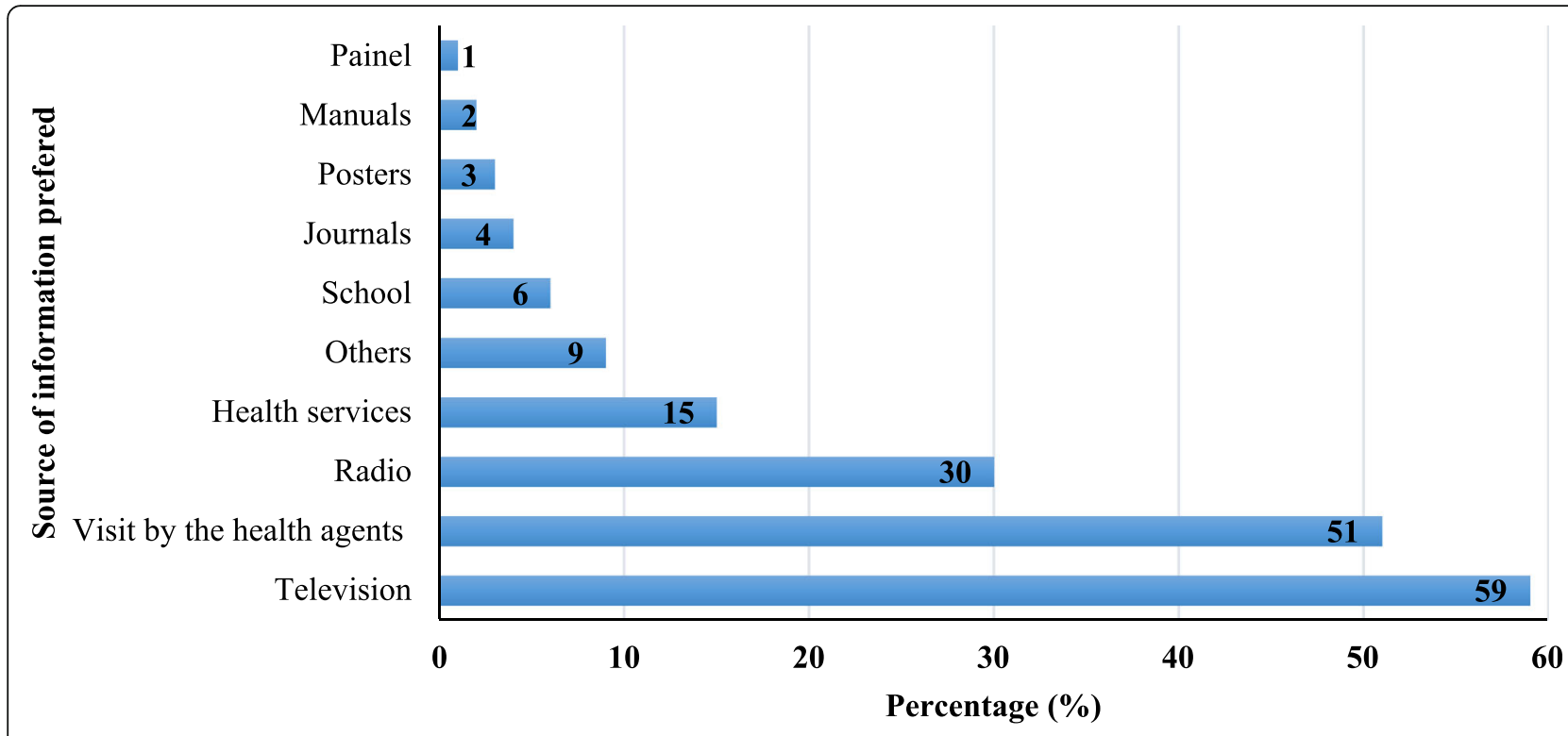

Fig. 5 The preferred source of information about malaria for the Cape Verdean population

are the determinants that more influence the complete knowledge of population (Table 5).

\section{Discussion}

The notable advances against malaria combined with scientific advances, had renewed the hope for malaria elimination in several WHO regions, one of which is Cape Verde. Nevertheless, to achieve the elimination goal and prevent resurgences of the disease, it is critical to implement strong and effective surveillance systems, to successfully and durably stop the transmission by detecting all possible malaria infections in the area in a timely manner [18]. This is where the important role of community

Table 4 The complete knowledge about malaria among the different population groups (sex. age and scholar level)

\begin{tabular}{lll}
\hline Characteristics & $\mathrm{n}$ (total) & Percentage \%) \\
\hline Sex & & \\
Male & $329(546)$ & 60.3 \\
Female & $731(1407)$ & 52.0 \\
Age group & & \\
$\leq 29$ & $275(495)$ & 55.6 \\
$30-39$ & $250(412)$ & 60.7 \\
$\geq 40$ & $535(1046)$ & 51.1 \\
Scholar level & & \\
Analphabetic & $98(281)$ & 34.9 \\
Primary & $485(931)$ & 52.1 \\
Secondary & $402(642)$ & 62.6 \\
Higher & $75(99)$ & 75.8 \\
TOTAL & $1060(1953)$ & 54.3 \\
\hline
\end{tabular}

involvement and the practices of the populations, especially those most affected by the disease $[9,10]$.

This first study conducted in Cabo Verde to explore the different levels of knowledge of the population about malaria at the national level. The population besides to know the correct form of malaria transmission and main symptoms, also know that the entire population is at risk of being affected by the disease. The attitudes to seek for treatment to the nearest health structure upon the apparition of the symptoms is in according with the WHO recommendation. Despite the low use of mosquito nets, the population has heard about it and is available to use it, in conjugation with other preventive measures. The population received information about malaria from media, mainly the TV and the radio and they e the complete knowledge of the disease.

From 2010 to 2016, Cabo Verde has recorded a few cases of malaria [6], is considered by the $\mathrm{WHO}$ as potentially able to eliminate malaria by 2020 . However, an increase in 2016 and the outbreak recorded in 2017 with 446 cases [7], demonstrated weaknesses and challenges in the disease control.

Changes in the clinical epidemiology of malaria, such as the prevalence of asymptomatic carriers, changes in the spatial distribution of the disease becoming heterogeneous, with more local/focal and imported cases, emphasize the need to plan operationally viable strategies to timely and successfully identify all the reservoirs of parasites across all the residual malaria transmission areas [19]. Given the lack of up to date of the Cape Verdean knowledge, attitudes and practices about Malaria a KAP survey has been carried out to gather information to support the Elimination program, to better targeted 


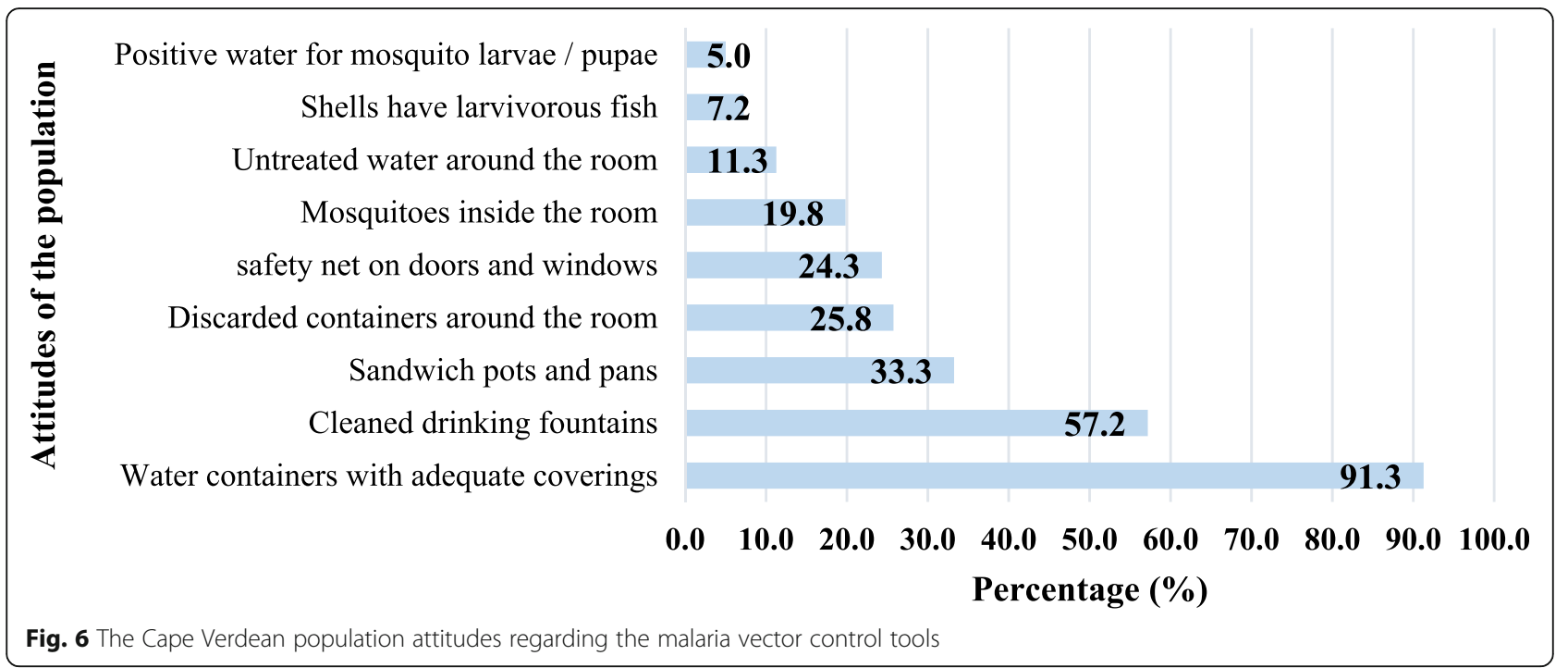

and adapted interventions, as well as increase targeted population ownership and participation and acceptance for/of current and future Public Health program. These aspects are considered of extreme significance in countries and territories with low endemicity of the disease, especially in Cape Verde, an archipelagic country, where the distribution of cases is not geographically uniform [20,21].

\section{Knowledge about malaria}

Malaria has been classified as the fifth of the six major diseases in the country, which is likely related to few malaria cases recorded in the country, between 2010 and 2016 compared to other countries in the sub-region $[6$, 7, 22-25]. Therefore, the Cape Verdean population, excepted in the islands of Santiago and Boavista, are less in contact with malaria in their daily lives, thus losing their knowledge about malaria. On the other hand, the few numbers of malaria imported cases, exclusively from endemic countries of Africa, mostly asymptomatic [22, 23], makes it difficult to manage them in the country.

Mosquito bite has been identified as the principal malaria transmission as shown in some studies in Africa, Asia and America [26-36]. However, our results were in contrast with those previously reported from Nigeria, where a small proportion of respondents correctly know the main malaria transmission route and its cause [37].

The Cape Verdean population is aware that the entire national population are susceptible to the disease and has correctly identified mains malaria symptoms. Fever was reported as the most common symptom of the disease, together with headache, vomiting, chill and muscle pain. This is consistent with what was reported previously [3739]. This high level of awareness about the disease, the modes of transmission and the clinical characteristics of malaria is likely to be related to the increased access to mass media, health education by health professionals, easy access of health services, as well as the reinforcement of door-to-door awareness campaigns carried out in recent years in Cape Verde [40].

\section{Aptitudes and practices of cape Verdean population toward malaria}

The study showed that the majority of Cape Verdean looks for treatment to the nearest health structure, suggesting a good coverage of and accessibility to health facilities across the country [41]. The same has been concluded in African countries [31, 32, 42, 43], with the majority of studies relating high malaria treatment-seeking behaviour at health facilities with the availability and easy

Table 5 Logistic regression on age, resident area and scholar level and the prediction on complete knowledge about malaria in the capeverdian population

\begin{tabular}{llll}
\hline Covariates and analysed sample & Total & Univariate Analysis & Multivariate analysis \\
\hline & Number (\%) & Crude OR $(95 \% \mathrm{Cl})$ & $\mathrm{AOR}^{\mathrm{a}}(95 \% \mathrm{Cl})$ \\
Age $(n=1953)$ & $1060(54.3 \%)$ & $1.12(1.01-1.25)$ & $0.71(0,61-0,82)$ \\
Resident area (municipality) (1953) & $1060(54.3 \%)$ & $1.00(0.99-1.01)$ & $0.99(0.99-1.00)$ \\
Scholar level & $1060(54.3)$ & $1.16(1.03-1.30)$ & $1.15(1.02-1.69)$ \\
\hline
\end{tabular}

${ }^{\mathrm{a} O R}$ Odds Ratio, AOR Adjusted Odds Ratio 
access of the latter. Conversely, this was not the case in Nigeria, where $47.6 \%$ of the population rely on selfmedication but not health structures to treat malaria [37].

About $64 \%$ of the Cape Verdean population, go to the nearest health service within the $24 \mathrm{~h}$ upon the apparition of the first malaria symptoms, even more (88\%) seek for treatment at health structures within the $48 \mathrm{~h}$. This is in line with the Abuja summit report on malaria, stating that at least $60 \%$ of people suffering from malaria should seek treatment within $24 \mathrm{~h}$ of the apparition of first symptoms [44]. Despite the good treatment-seeking behaviour of the Cape Verdean population, there still more to do to get the closest to $100 \%$ of patients timely seeking treatment at the closest health facilities. Indeed, according to the WHO [45], the early search for treatment at the health structure is essential to interrupt the local transmission cycle of malaria, especially during the elimination phase. At this stage, the surveillance system should be able to detect all malaria infections and ensure radical treatment. Therefore, the awareness and collaboration of the population to directing themselves timely toward health structures earlier upon the apparition of malaria symptoms are crucial.

The results reported here are critical and encouraging in the context of the Cape Verdean malaria elimination programme, indeed, the study population displays a high level of knowledge about malaria symptoms and people know that the best behaviour when they are sick is to immediately seek for treatment at the nearest health structure. This knowledge must be transformed into routine attitudes and practices all over the country [46] to early detect all malaria infections, as required in malaria elimination strategies in the country [41] and the WHO elimination policies [42, 43, 47].

While in some African countries, there is a strong tradition of using mosquito bed nets against malaria [48-53], this strategy is not very common Cabo Verde [40]. However, the population awareness about the bed nets and their willingness to use them if easily available will facilitate their diffusion in the country. In fact, ITNs are widely accepted and used in several African countries, even in areas with no previous or low experience about the tool $[42,54]$. Despite being influenced by seasonal factors, preferences criteria and cost, nets have been and still one of the cores if not the unique vector control strategy in some Africa's settings with high availability (99\% of households having at least one net). Nets are being mainly (76\%) used throughout the year and, mainly during seasons of high densities of mosquitoes. In Cabo Verde, the low use may be associated with the non-adoption of this strategy by the National Malaria Control Program (NMCP) over the last years. The archipelago is not the unique case where low usage of mosquito nets against malaria has been reported. In South
Africa, nets usage does not exceed 2\% [42]. However, it is worth to note that despite being not implemented as a national malaria control strategy, The Cape Verdean NMCP is being gradually introducing and encouraging net usage as a personal protection measure with free distribution to all confirmed and hospitalized malaria patients, especially in places of high transmission risk.

Despite the efforts made so far to malaria control in Cabo Verde, social awareness in some aspects of the disease still need to be strengthened. This is particularly true when asking about who should be the stakeholders of mosquito's control within the community. Most people think that that the population alone or health structures alone are responsible for the actions to be taken, while only a small part believe both should joint their effort to control vector, and thus the diseases they transmit. On the other hand, most respondents believe that malaria is preventable, but few of them still thinking that there no need for personal protection against infection or opt for other non-conventional strategies. Therefore, the issue of not combating malaria may be associated with the people dependence on local health structures for malaria control interventions. Moreover, the lack of knowledge of the most correct actions needs to be further studied.

Interviewees have a good knowledge of environmental actions as good preventive measures, among which the main measures consisted for them to eliminate breeding sites at the community level. This has been revealed in other studies in Nigeria [55] and Ethiopia [56], where the study population saw environmental management as an efficacious mosquitos control strategy. However, knowledge has not always been translated into the improved practice of preventive measures. Therefore, targeted and adapted actions should be developed to empower the Cape Verdean populations for best practices, given the low socioeconomic level and the low level of formal education of rural communities.

IRS is one of the main vector-borne diseases control strategies, especially against malaria [57]. Most of the participant's knowledge IRS importance to control mosquitoes and consequently malaria. However, only $42.9 \%$ of households were sprayed within the last 12 months preceding the survey. This is lesser than the WHO recommended minimum IRS coverage rate of $80 \%$ for community protection [56]. Unfortunately, the same has been reported from several other countries [28, 42, 56, 58]. But, countries such as the Swaziland where IRS coverage was above $80 \%$, shows that the goal could be achieved with the increase of the commitment of local stakeholder and community [35].

\section{Source of information on malaria}

The television, radio as well as community sensitisation by health agent's visits, have been identified most as main 
sources of information about malaria in Cape Verde as shown in South Africa [42]. In contrast, in Swaziland information about malaria were mainly retrieved from health facilities in 2009 [35]. Our results have revealed that most of the Cape Verdeans are well informed about malaria and understand well the information they receive. Which is very interesting, given the malaria low incidence in the country. In fact, not being affected by the disease may contribute to the decrease of the awareness about it. Moreover, only hearing about malaria is not enough but should be the basis addressing a whole range of issues about the disease, especially to increase knowledge about the form of transmission, the main symptoms, preventive measures and treatment.

Besides the conventional media such as TV and radio, technological advances offer new avenues to increase the population awareness about malaria-associated issues in Cabo Verde. Indeed, phone and SMS, as well as new social media platforms, should not be ignored as potential and very accessible source of information. This is particularly true concerning the specificities of each island regarding the educational level of the population; and despite the majority of the population prefer being informed through television or visits by health workers and mainly in Creole, their local language.

\section{Complete knowledge of malaria}

In summary, the complete local population knowledge about malaria, including transmission routes, symptoms and main preventive measure showed that more than half of people know enough about malaria, which is strongly correlated with the level educational. Therefore, the relatively high frequency of illiteracy among the participants (14.4\%) plays a key role in limiting the acquisition of knowledge or awareness about malaria. This is very important in a context where malaria was no longer a huge public health problem in the country, until the recent outbreak [6].

This study also revealed significant differences in protective measure against mosquito bites, such as the use of mosquito nets and sprays cans to prevent malaria transmission. Therefore, it is urgently needed to promote equal as well as universal access and usage of malaria preventive measures to get back on track of the malaria elimination goal in Cabo Verde, especially in Santiago and Boavista islands where all the malaria indigenous cases were in 2017 [6]. This is also true to prevent the re-introduction of malaria once the archipelago would be declared malaria-free.

To that aim, great importance must be given to behaviour change communication (BCC) strategic using targeted messages and personalized approaches to promote healthy behaviours and reduce risks [59]. In Cabo Verde, $\mathrm{BCC}$ mechanisms and community involvement, using the new tools and strategies for malaria elimination still a big challenge [19], as shown by the local population participation in mosquito control activities. Indeed, only less than $40 \%$ of the study population reported having previously participated in some vector control activities. Strong evidence exist elsewhere on the key role that must be played by $\mathrm{BBC}$ to improving malaria control and prevention as well as treatment-seeking behaviours [60-64]. For instance, the promotion of screening and treatment of malaria in hotspots areas in Zanzibar or the use of nets and prophylaxis for travellers in Swaziland [65], have led to a significant decrease of malaria incidence. Other aspects for which $\mathrm{BCC}$ is fundamental concern the screening and detection of asymptomatic individuals requiring some time mass diagnosis and treatment of as much as possible individuals or communities [66]. These two essential aspects should be reinforced in Cabo Verde, considering the circumscription of indigenous malaria cases in wellidentified hotspot locations.

The country-level Malaria Communication Strategic Framework [67] argues that well-planned and wellimplemented communication programs can contribute to achieving multi-level malaria prevention and treatment targets. These findings of this study demonstrate that the behavioural change communication strategies should be updated and adapted to the changing profile of the disease transmission and the risk of transmission to achieve the elimination in Cabo Verde. Also, timely studies should be implemented frequently to gather evidence to adapt messages and approaches, reduce audience scorn, promote new interventions and solidify the evidence base that allows adapting efforts to respond to demands on the process of malaria in Cabo Verde.

\section{Conclusion}

Overall, the study revealed that the Cape Verdean population has a high of knowledge about malaria, including its mode of transmission, main symptoms, adequate behaviours towards its treatment and main preventive measures. However, some gaps and misunderstandings persist about the disease, being strongly correlated to the level of education.

The population usually seek for treatment to the nearest health structure within the first 24 or $48 \mathrm{~h}$ after the apparition of main malaria symptoms. However, attitudes and practices regarding preventive measure need to be improved. Some barriers make the control actions unsatisfactory and undesirable, reflected by ignorance and/or indifference of the targeted population about malaria prevention. Adapting strategies to increase knowledge of the population, including the malaria transmission, the benefits of preventive measures and the availability of effective individual and community control tools, need to be strengthened the malaria elimination process in Cabo Verde. 


\section{Additional files}

Additional file 1: Interview Guide used in KAP Study (DOCX 27 kb)

\section{Abbreviations}

BCC: Behaviour Change Communication; CNEPS: Comité Nacional de Ética e Pesquisas em Saúde; IRS: Indoor Residual Spray; ITNs: Insecticide-treated bed nets; KAP: Knowledge, attitudes and practices; NMCP: Nacional Malaria Control Program; SPSS: Statistical Package for the Social Sciences; SQD: Squares of distances; WHO: World Health Organisation

\section{Acknowledgements}

The authors express our utmost gratitude to the Cape Verdean population who voluntarily responded the questionnaire. We are grateful to the heath delegations in the municipalities and island where the stud carried out and to the team who worked in the data collection on the field. We thank the NMCP members who works constantly with the malaria research in Cabo Verde. We also thank Jose Fernandes, from Faculdade de Ciências e Tecnologia da Universidade de Cabo Verde, for his support in data analysis and apecial acknowledge to Theresia Estomih Nkya, International Centre of Insect Physiology and Ecology, Nairobi, Kenya for the for reading and copyediting the paper

\section{Authors' contributions}

ADP, AASM, MCF, ALM, SVL, CMP, MFT and JMGM conceived the study idea, participated in study design; data acquisition. ADP and ASMM participated in the data analysis and interpretation; ADP, AKD, AM, JMP and AJFM drafting and manuscript drafting and critically reviewed the manuscript; EHAN, OF and IS supported conception of the idea, reviewed the data and helped with manuscript drafting and critically reviewed the manuscript. All authors read and approved the final manuscript.

\section{Funding}

This study was funded by The Global Fund to Fight AIDS, Tuberculosis and Malaria, through the Program Malaria Pre-Elimination in Cabo Verde, grant CPV-M-CCSSIDA, number 763. The funder had no role in study design, data collection and analysis, decision to publish, or preparation of the manuscript.

\section{Availability of data and materials}

We did not obtain consent to share data obtained from the questionnaire and key informant interviews, however the datasets used and/or analysed during the current study available from the corresponding author on reasonable request.

\section{Ethics approval and consent to participate}

The study was approved by the National Ethics and Health Research Committee (CNEPS, in Portuguese), in accordance with resolution 18/2017. All respondents provided written informed consent after receiving detailed description of the study. Eligible participants were consented in privacy and no incentives were given. Anonymity of the respondents was ensured in all stages of data analysis.

\section{Consent for publication}

Not Applicable.

\section{Competing interests}

The authors declare that they have no competing interests.

\section{Author details}

${ }^{1} E$ Ecole Doctorale des Sciences de la Vie, de la Santé et de l'Environnement (ED-SEV), Université Cheikh Anta Diop (UCAD) de Dakar, Dakar, Sénégal. ${ }^{2}$ Programa de Pré-Eliminação do Paludismo, CCS-SIDA. Ministério da Saúde e da Segurança Social, Avenida Cidade Lisboa, Prêdio Bô Casa, $1^{\circ}$ Andar; CP, 855 Praia, Cabo Verde. 'Laboratoire d'Ecologie Vectorielle et Parasitaire, Faculté des Sciences et Techniques, Université Cheikh Anta Diop (UCAD) de Dakar, Dakar, Sénégal. ${ }^{4}$ Faculdade de Ciências e Tecnologia, Universidade de Cabo Verde, Praia, Cabo Verde. ${ }^{5}$ Unidade de Seguimento e Avaliação, CCS-SIDA. Ministério da Saúde e da Segurança Social, Praia, Cabo Verde. ${ }^{6}$ Programa Nacional de Luta contra o Paludismo, Ministério da Saúde e da Segurança Social, Praia, Cabo Verde. 'Laboratório de Entomologia Médica,
Instituto Nacional de Saúde Pública, Praia, Cabo Verde. ${ }^{8}$ Unidade de Unidade Microbiologia Médica; Departamento de Virologia, Instituto de Higiene e Medicina Tropical, Lisbon, Portugal. ' Laboratório de Análises Clínica, Hospital Regional de Santiago Norte, Assomada, Cabo Verde. ${ }^{10}$ Delegacia de Saúde da Praia, Praia, Cabo Verde. ${ }^{11}$ Rede Nacional de Laboratório, Ministério da Saúde e da Segurança Social, Praia, Cabo Verde. ${ }^{12}$ Unidade da Unidade de Ciências da Natureza, da Vida e do Ambiente. Universidade Jean Piaget de Cabo Verde, Praia, Cabo Verde. ${ }^{13}$ Laboratório de Engenharia Civil, Praia, Cabo Verde. ${ }^{14}$ Institut de Santé et Développement, Université Cheikh Anta Diop (UCAD) de Dakar, Dakar, Sénégal. ${ }^{15}$ Aix Marseille Univ, IRD, AP-HM, MEPHI, IHU-Méditerranée Infection, Marseille, France.

Received: 21 January 2019 Accepted: 9 June 2019

Published online: 01 July 2019

\section{References}

1. WHO. World malaria report 2018. Geneva: World Health Organization; 2018.

2. Cambournac FC, Petrarca V, Coluzzi M. Anopheles arabiensis in Cape Verde archipelago. Parassitologia. 1982;14(2):265-7.

3. Meira MT, Nogueira JF, Simões TS. Observações sobre sezonismo nas Ilhas do Sal, Boa Vista e S. Nicolau (Cabo Verde). An Inst Med Trop. 1947:4:213-38.

4. WHO. Moving towards sustainable elimination in Cape Verde. Eliminating malaria case study 2: World Health Organization; 2012. https://www.who.int/ malaria/publications/atoz/9789241504386/en/.

5. PNLP. Programa Nacional de Luta Contra o Paludismo. Revisão da performance do programa nacional de luta contra o paludismo, Relatório Geral. Praia, Cabo Verde, 2013.

6. DePina AJ, Niang AH, Andrade AJ, Dia AK, Moreira A, Faye O, et al. Achievement of malaria pre-elimination in Cape Verde according to the data collected from 2010 to 2016. Malaria J. 2018;17(1):236.

7. DePina AJ, Andrade AJ, Dia AK, Moreia AL, Furtado UD, Baptista H, et al. Spatiotemporal characterization and risk factor analysis of malaria outbreak in Cabo Verde in 2017. Trop Med Health. 2019;47:3.

8. Dlamini SV, Liao AW, Dlamini ZH, Siphepho JS, Cheng PC, Fan CK. Knowledge of human social and behavioural factors essential for the success of community malaria control intervention programs: the case of Lomahasha in Swaziland. J Microbiol Immunol Infect. 2017;50:245-53.

9. Adhikari B, Phommasone K, Pongvongsa T, Kommarasy P, Soundala X Henriques $\mathrm{G}$, et al. Factors associated with population coverage of targeted malaria elimination (TME) in southern Savannakhet Province, Lao PDR. Malar J. 2017;16:424.

10. Adhikari B, Pell C, Phommasone K, Soundala X, Kommarasy P, Pongvongsa $T$, et al. Elements of effective community engagement: lessons from a targeted malaria elimination study in Lao PDR (Laos). Glob Health Action. 2017:10:1366136.

11. Pell CL, Adhikari B, Myo Thwin M, Kajeechiwa L, Nosten S, Nosten FH, et al. Community engagement, social context and coverage of mass anti-malarial administration: comparative findings from multi-site research in the greater Mekong sub-region. PLoS One. 2019;14(3):e0214280.

12. Adhikari $B$, Phommasone $K$, Pongvongsa $T$, Soundala $X$, Koummarasy $P$, Henriques $G$, et al. Perceptions of asymptomatic malaria infection and their implications for malaria control and elimination in Laos. PLoS One. 2018; 13(12):e0208912.

13. Adhikari B, James N, Newby G, Seidlein L, White NJ, Day NP, et al. Community engagement and population coverage in mass anti-malarial administrations: a systematic literature review. Malar J. 2016;15:523.

14. Adhikari B, Phommasone $K$, Kommarasy $P$, Soundala $X$, Souvanthong $P$, Pongvongsa $\mathrm{T}$, et al. Why do people participate in mass anti-malarial administration? Findings from a qualitative study in Nong District, Savannakhet Province, Lao PDR (Laos). Malar J. 2018;17:15.

15. INE. Instituto Nacional de Estatística. Projecção da População de Cabo Verde. 2010-2030. In: Cabo Verde; 2010

16. Simão FB, Landim PM. Estatistica Espacial Multivariada: Endemia da Malária em Porto Velho-RO: Este texto é um estudo de Caso, baseado em uma modelagem multivariada espacial. Portuguese edition. Novas Edições Académicas; 2018

17. de Oliveira EC, dos Santos ES, Zeilhofer P, Souza-Santos R, Atanaka-Santos M. Geographic information systems and logistic regression for highresolution malaria risk mapping in a rural settlement of the southern Brazilian Amazon. Malar J. 2013;12:420. 
18. Liu J, Modrek S, Goslin RD, Feachem RG. Malaria eradication: is it possible? Is it worth it? Should we do it? Lancet Glob Health. 2013;1(1):e2-3.

19. Hemingway J, Shretta R, Wells TN, Bell D, Djimdé AA, Achee N, et al. Tools and strategies for malaria control and elimination: what do we need to achieve a grand convergence in malaria? PLoS Biol. 2016;14(3):e1002380.

20. WHO. Malaria elimination: a field manual for low and moderate endemic countries: World Health Organization; 2007. https://www.who.int/malaria/ publications/atoz/9789241511988/en/.

21. Tanner M, Greenwood B, Whitty CJ, Ansah EK, Price RN, Dondorp AM, et al. Malaria eradication and elimination: views on how to translate a vision into reality. BMC Med. 2015;13:167.

22. CCS-SIDA. Comité de Combate e Coordenação ao VIH. Formulaire de Demande de reconduction du Programme au Fonds Mondial de la lutte contre le VIH. Tuberculosis and Paludisme. 2017;1:1-23.

23. Moukah MO, Ba O, Ba H, Khairy ML, Faye O, Bogreau H, et al. Malaria in three epidemiological strata in Mauritania. Malar J. 2016;15:204.

24. Espié E, Sarr FD, Diop F, Faye J, Richard V, et al. Spatio-temporal variations in malaria incidence in children less than 10 years old, Health District of Sokone, Senegal. 2010-2013. PLoS One. 2015;10(9):e0137737.

25. Kiszewski AE, Tekelehaimanot A. A review of the clinical and epidemiologic burdens of epidemic malaria. Am J Trop Med Hyg. 2004; 71(Suppl 2):128-35.

26. Mora-Ruiz M, Penilla RP, Ordóñez JG, López AD, Solis F, Torres-Estrada $J$, et al. Socioeconomic factors, attitudes and practices associated with malaria prevention in the coastal plain of Chiapas, Mexico. Malar J. 2014;13:157.

27. Hong YS, Lee D-K, Yoon J-H, Sohn A. Knowledge and practice on malaria among Korean soldiers in nearby demilitarized zone, in South Korea. Iran J Public Health. 2017;46(9):1184-92

28. Khairy S, Al-Surimib K, Ali A, Shubilyd HM, Al Walaan N, Househ M, et al. Knowledge. Attitude and practice about malaria in South-Western Saudi Arabia: a household-based cross-sectional survey. J Infect Public Health. 2017;10:499-506.

29. Chovatiya SK, Gajera NB, Soni PV. People's perception on malaria: a case study in rural areas of Rajkot District, Gujarat-India. Health Sci Int J. 2013;2(1): $1-5$.

30. Ganfon H, Ekanmian G, Amoussou L, Daniel-Garcia E, Allabi AC. Evaluation of the knowledge and attitude of pharmacists about the national malaria control policy in southern Benin. Malar J. 2017;16:231.

31. Yaya S, Bishwajit G, Ekholuenetale M, Shah V, Kadio B, Udenigwe O. Knowledge of prevention, cause, symptom and practices of malaria among women in Burkina Faso. PLoS One. 2017;2(7):e0180508.

32. Taremwa IM, Ashaba S, Adrama HO, Ayebazibwe C, Omoding D, Kemeza I, et al. Knowledge. Attitude and behaviour towards the use of insecticide treated mosquito nets among pregnant women and children in rural southwestern Uganda. BMC Public Health. 2017;17:794.

33. Paulander J, Olsson H, Lemma H, Getachew A, San Sebastian M. Knowledge, attitudes and practice about malaria in rural Tigray, Ethiopia. Glob Health Action. 2009;2. https://doi.org/10.3402/gha.v2i0.1839.

34. Alilio MS, Bammek J. A KAP study in Zanzibar: implications for prevention and control: a study conducted for UNICEF suboffice Zanzibar. Eval Program Plann. 1998;21:409-13.

35. Hlongwana KW, Mabaso ML, Kunene S, Govender D, Maharaj R. Community knowledge, attitudes and practices (KAP) on malaria in Swaziland: a country earmarked for malaria elimination. Malaria J. 2009;8:29.

36. Adongo PB, Kirkwood B, Kendall C. How local community knowledge about malaria affects insecticide treated net use in northern Ghana. Tropical Med Int Health. 2005;10:366-78.

37. Singh R, Musa J, Singh S, Ebere UV. Knowledge, attitude and practices on malaria among the rural communities in Aliero, northern Nigeria. J Fam Med Prim Care. 2014;3:39-44.

38. Deressa W, Ali A, Enquoselassie. Knowledge, attitude and practice about malaria, the mosquito and antimalarial drugs in a rural community. Ethiop J Health Dev. 2003;17:99-104.

39. Mazigo HD, Obasy E, Mauka W, Manyiri P, Zinga M, Kweka EJ, et al. Knowledge, attitudes, and practices about malaria and its control in rural Northwest Tanzania. Malaria Research and Treatment. 2010;794261:9.

40. DePina A. O envolvimento da população e da Sociedade civil no Combate ao Paludismo no âmbito de Pré- Eliminação da doença em Cabo Verde. Revista da Ordem dos Médicos Cabo-verdianos. 2015;2(18):30-40.
41. PNLP. (Programa Nacional de Luta Contra o Paludismo). Plano Estratégico Nacional da Pré-Eliminação do Paludismo, 2014 - 2017. Ministério da Saúde de Cabo Verde; Praia, Cabo Verde, 2014.

42. Manana PN, Kuonza L, Musekiwa A, Mpangane HD, Koekemoer LL. Knowledge, attitudes and practices on malaria transmission in Mamfene, KwaZulu- Natal Province, South Africa, 2015. BMC Public Health. 2017;18:41.

43. Musoke D, Karani G, Ssempebwa JC, Etajak S, Guwatudde D, Musoke MB. Knowledge and practices on malaria prevention in two rural communities in Wakiso District, Uganda. Afr Health Sci. 2015;15(2):401-12.

44. WHO. The Abuja declaration on roll Back malaria in Africa, African heads of states and governments: World Heatlh Organisation; 2000. https://au.int/ sites/default/files/pages/32894-file-2000_abuja_declaration.pdf.

45. WHO. Disease surveillance for malaria elimination: an operational manual. WHO library cataloguing-in-publication data. Geneva: World Health Organization; 2012.

46. WHO. A framework for malaria elimination; World Health Organization 2017 WHO library cataloguing-in-publication. Geneva: World Health Organization; 2017.

47. WHO. Action and investment to defeat malaria 2016-2030. For a malaria-free world. World Health Organization on behalf of the roll Back malaria partnership secretariat 2015; WHO library cataloguing-inpublication data; 2015.

48. Ziba C, Slutsker L, Chitsulo L, Steketee RW. Use of malaria prevention measures in Malawian households. Trop Med Parasitol. 1994;45(1):70-3.

49. Nkumama IN, O'Meara WP, Osier FH. Changes in malaria epidemiology in Africa and new challenges for elimination. Trends Parasitol. 2017; 33(2):128-40.

50. D'Alessandro U, Aikins MK, Langerock P, Bennett S, Greenwood BM. Nationwide survey of bednet use in rural Gambia. Bull World Health Organ. 1994;72(3):391-4.

51. D'Alessandro U, Langerock P, Francis N, Greenwood BM. The impact of a national impregnated bednet programme on the outcome of pregnancy in Gambian primigravidae. Trans R Soc Trop Med Hyg. 1996;90:487-92.

52. Binka FN, Kubaje A, Adjuik M, Williams LA, Lengeler C, Maude GH, et al. Impact of permethrin impregnated bednets on child mortality in KassenaNankana district. Ghana: a randomized controlled trial. Tropical Med Int Health. 1996;1 (2):147-54.

53. Tomass Z, Alemayehu B, Balkew M, Leja D. Knowledge, attitudes and practice of communities of Wolaita, southern Ethiopia about long-lasting insecticidal nets and evaluation of net fabric integrity and insecticidal activity. Parasit Vectors. 2016;9:224.

54. Gyapong M, Gyapong JO, Amankwa J, Asedem J, Sory E. Introducing insecticide impregnated bednets in an area of low bednet usage: an exploratory study in north-East Ghana. Tropical Med Int Health. 1996;1:328-33.

55. Olayemi IK, Omalu IC, Abolarinwa SO, Mustapha OM, Ayanwale VA, Mohammed $A Z$, et al. Knowledge of malaria and implications for control in an endemic urban area of north Central Nigeria. Asian J Epidemiol. 2012;5:42-9.

56. Abate A, Degarege A, Erko B. Community knowledge, attitude and practice about malaria in a low endemic setting of Shewa Robit town, northeastern Ethiopia. BMC Public Health. 2013;8:13-312.

57. Indoor residual spraying: use of indoor residual spraying for scaling up global malaria control and elimination: WHO position statement: WHO; 2006. https:// apps.who.int/iris/handle/10665/69386.

58. Joshi A, Banjara M. Malaria related knowledge. Practices and behaviour of people in Nepal. J Vector Borne Dis. 2008;45(1):44-50.

59. Koenker H, Keating J, Alilio M, Acosta A, Lynch M, Nafo-Traore F. Strategic roles for behaviour change communication in a changing malaria landscape. Malar J. 2014;13:1.

60. Kilian A, Lawford H, Ujuju CU, Abeku TA, Nwokolo E, Okoh F, et al. The impact of behaviour change communication on the use of insecticide treated nets: a secondary analysis of ten post-campaign surveys from Nigeria. Malar J. 2016;15:422.

61. Keating J, Hutchinson P, Miller JM, Bennett A, Larsen DA, Hamainza B, et al. A quasi-experimental evaluation of aninterpersonal communication intervention to increase insecticide-treated net use among children in Zambia. Malaria J. 2012;11:313.

62. Minja H, Schellenberg JA, Mukasa O, Nathan R, Abdulla S, Mponda H, et al. Introducing insecticide-treated nets in the Kilombero Valley. Tanzania: the relevance of local knowledge and practice for an information. Education and communication (IEC) campaign. Tropical Med Int Health. 2001;6:614-23. 
63. Deribew A, Birhanu Z, Sena L, Dejene T, Reda AA, Sudhakar M, et al. The effect of household heads training on long-lasting insecticide-treated bed nets utilization: a cluster randomized controlled trial in Ethiopia. Malar J. 2012;11:99.

64. Bowen HL. Impact of a mass media campaign on bed net use in Cameroon. Malaria J. 2013;12:36.

65. Snow W, Guerra CA, Noor AM, Myint HY, Hay SI. The global distribution of clinical episodes of Plasmodium falciparum malaria. Nature. 2005:434(7030): 214-7.

66. Cotter C, Sturrock HJ, Hsiang MS, Liu J, Phillips AA, Hwang J, et al. The changing epidemiology of malaria elimination: new strategies for new challenges. Lancet. 2013;382:900-11.

67. RBM. Roll Back malaria. Strategic framework for malaria communication at the country level 2012-2017. Geneva: Roll Back Malaria; 2012.

\section{Publisher's Note}

Springer Nature remains neutral with regard to jurisdictional claims in published maps and institutional affiliations.

- fast, convenient online submission

- thorough peer review by experienced researchers in your field

- rapid publication on acceptance

- support for research data, including large and complex data types

- gold Open Access which fosters wider collaboration and increased citations

- maximum visibility for your research: over $100 \mathrm{M}$ website views per year

At BMC, research is always in progress. 